\title{
CONHECIMENTOS DOCENTES DE LICENCIANDOS EM MATEMÁTICA NO ÂMBITO DA FORMAÇÃO E AÇÕES DESENVOLVIDAS NO PIBID DO IFCE CANINDÉ
}

\author{
Francisca Renata Silva Barbosa, Ana Cláudia Gouveia de Sousa, \\ Luciana de Oliveira Souza Mendonça, Samara Moura Barreto de Abreu \\ Instituto Federal de Educação Ciência e Tecnologia do Ceará - IFCE, Campus de Canindé \\ $<$ renatapoetisa@hotmail.com>, <anaclaudiaifce@gmail.com> \\ <professoralucianamendonca@gmail.com> <samaraef@ hotmail.com> \\ DOI: $10.21439 /$ conexoes.v9i4.992
}

\begin{abstract}
Resumo. A discussão acerca da formação de professores tem exigido inúmeras pesquisas, dentre elas destacam-se os temas acerca dos programas de formação inicial e continuada. Nisto entra em cena o Programa Institucional de Bolsa de Iniciação à Docência - PIBID, que objetiva inserir o licenciando em contato direto com a escola a partir da práxis permeada nas diversas atividades nas escolas parceiras do programa. Dentro desse contexto, o Subprojeto "Re-construindo conhecimentos matemáticos" do IFCE - Campus de Canindé apresenta-se como proposta de aperfeiçoamento dos futuros professores da área, tendo como premissa básica oportunizar ações formadoras que favoreçam o desenvolvimento de práticas pedagógicas, proporcionando a esses licenciandos uma postura reflexiva sobre o ensino e aprendizagem de matemática. Assim, o presente texto relata uma pesquisa que objetivou analisar os conhecimentos construídos e explorados pelos licenciandos em matemática do IFCE - Campus de Canindé mediante atuação no PIBID. Para responder ao problema central da pesquisa lançamos mão de uma abordagem qualitativa de investigação, realizando uma pesquisa de campo do tipo estudo de caso, através da aplicação de um questionário semiestruturado a 19 graduandos/bolsistas do PIBID, como instrumento de coleta de dados. A análise desses dados foi feita com base na análise de conteúdo, e tomou como aporte teórico principal a base de conhecimentos docentes de Shulman (1986; 2005). Diante da pesquisa os resultados apontam diversificados conhecimentos construídos e ressignificados pelos sujeitos investigados a partir da participação efetiva no PIBID da forma como realizado, materializando-o como significativo na apreensão dialética e reflexiva do ser e fazer docente.
\end{abstract}

Palavras-chaves: Formação de Professores. Ensino de Matemática. Conhecimentos Docentes.

\begin{abstract}
The discussion of teacher education has required extensive research, among which stand out those issues of initial and continuing education programs. It comes into play the Institutional Program Initiation Purse in Teaching - PIBID, which aims to enter the licensee in direct contact with the school from the praxis permeated the various activities in partner schools program. In this context, the Subproject "Re-building mathematical knowledge of IFCE - Campus Caninde is presented as an improvement purpose of future teachers in the area, with the basic premise enable forming actions that favor the development of teaching practices, providing these students write one reflexive position on the teaching and learning of mathematics. The present paper reports a study that aimed to analyze the knowledge built and operated by undergraduates in mathematics IFCE - Campus Caninde by acting in PIBID. To answer the central research problem lay hold of a qualitative research approach, conducting a field survey of the type case study, by applying a semi-structured questionnaire to 19 graduate students / fellows PIBID, such as data collection instrument. Data analysis was based on content analysis, and took as its main theoretical contribution to basic knowledge of teachers Shulman $(1986,2005)$. On the survey results point diversified knowledge built and resignified by the subjects investigated from effective participation in PIBID the way done materializing it as significant in apprehension dialectic and reflexive of to be and make teaching.
\end{abstract}

Keywords: Initial Training. PIBID. Mathematics Teaching. Teachers knowledge. Conex. Ci. e Tecnol. Fortaleza/CE, v. 9, n. 4, p. 67 - 77, dez. 2015 


\section{INTRODUÇÃO}

A mudança do papel do professor ao longo do tempo tem sido apontada em estudos como os de Curi e Pires (2008), onde o docente é visto como um agente de mudanças, que confronta de forma reflexiva as diversas situações que ocorrem no ambiente escolar, uma vez que as novas tendências do ensino requerem dele uma atuação não mais de transmissão de saber, mas de um profissional em permanente formação.

Nessas pesquisas o professor não é mais concebido como mero reprodutor de saberes e práticas cristalizadas, mas como um profissional que conhece, reflete, cria e recria (CURI; PIRES, 2008). Por isso compreendemos, no âmbito desse trabalho, que a formação de um professor de matemática deve caminhar no sentido de formar o professor reflexivo (SCHÖN, 2000; PIMENTA, 2012); e também formar um profissional que tenha tanto o conhecimento matemático como os conhecimentos didático-pedagógicos para o ensino da matemática, como afirma Shulman (1986).

Nessa perspectiva, faz-se necessário que os programas de formação de professores, incorporem também situações práticas desde o início da formação, interligando a parte teórica com a prática, promovendo assim, durante a formação, experiências em sala de aula que permitam ao futuro professor a reflexão, investigação e análise do ambiente escolar.

O Programa Institucional de Bolsa de Iniciação à Docência (PIBID) tem sido uma Política Nacional de Educação, e mais especificamente de Formação, que vai nesse sentido. Ele oportuniza a inserção dos licenciandos na escola pública "desde o início da sua formação acadêmica para que desenvolvam atividades didáticopedagógicas sob orientação de um docente da licenciatura e de um professor da escola" (CAPES, 2008, s /p) $\mathrm{E}$, ainda, constitui-se num dos caminhos para promover a integração entre a Educação Superior e a Educação Básica, na busca pelo fortalecimento da formação inicial para a docência e da melhoria da qualidade do ensino e aprendizagem na escola básica.

O interesse por estudar essa temática está relacionado também com a nossa trajetória no PIBID/Matemática/IFCE - Campus de Canindé, seja como bolsista de iniciação à docência ou como professor bolsista coordenador de área ou professor colaborador. Para além do que preconizam os documentos do PIBID, também no plano individual, temos experimentado frutos dessa política pública, tanto no tocante à formação pessoal e profissional quanto a uma aproximação produtiva entre escola pública e Instituição de

1 Portal do PIBID
educacao-basicacapespibid $>$

Ensino Superior - IES.

Uma aproximação de muitos aprendizados, tanto com as potencialidades como com os dilemas ${ }^{2}$ para fazer acontecer. E que tem nos ajudado a refletir sobre as próprias experiências e questionar como, de fato, essas experiências têm se incorporado, como conhecimentos e práticas, à formação dos bolsistas PIBID de Matemática do IFCE/Canindé?; O que tem sido aprendido por eles no campo da prática, especificamente no tocante ao conhecimento matemático para o ensino? O PIBID Matemática do IFCE/Canindé conta hoje com 20 bolsistas nessa área e a primeira turma de formados está saindo ao final de 2015. Até que ponto o PIBID tem deixado "marcas" na formação desses futuros egressos, e que marcas são essas?

Assim, julgamos necessário um estudo local do tipo estudo de caso, que possa responder à pergunta central: Que conhecimentos os licenciandos em Matemática do IFCE - Campus de Canindé estão adquirindo mediante participação no PIBID?

Esse estudo se justifica ainda para compreender como o PIBID se torna iniciativa potencial para fortalecer a formação inicial do professor de matemática. Dessa forma, o objetivo central do estudo que gerou este artigo foi analisar os conhecimentos construídos e explorados pelos licenciandos em matemática do IFCE - Campus de Canindé mediante atuação no PIBID. Para tanto, tivemos como objetivos específicos: Identificar conhecimentos adquiridos ou ressignificados, assim como analisar os conhecimentos presentes nas falas de licenciandos em Matemática sobre a sua formação e/ou atuação como bolsista PIBID, a partir das categorias preconizadas por Shulman.

Este trabalho segue apresentando, inicialmente, uma breve reflexão a respeito da Formação Inicial de professores de Matemática, o PIBID, um breve panorama das ações desenvolvidas no Subprojeto Matemática do IFCE - Campus de Canindé e ainda alguns conhecimentos docentes ${ }^{3}$ discutidos por autores que se preocupam com a formação de professores.

\section{FORMAÇÃO INICIAL, PIBID E CONHECI- MENTOS DOCENTES}

Passamos a discutir, a seguir, a formação inicial específica do professor de Matemática, com seus desdobra-

\footnotetext{
${ }^{2}$ Ancorado em Sacristán (1999) entendemos que "os dilemas representam os pontos de conflito e insegurança da estrutura de esquemas, desde o nível mais pragmático, passando pelos esquemas estratégicos, até as ideias e valores de base que sustentam a articulação ação-pensamento" (p. 87).

${ }^{3}$ As traduções utilizadas foram realizadas pelas autoras deste trabalho, a fim de facilitar a compreensão das categorias apresentadas por Shulman (2005).
} 
mentos relativos à prática, notadamente no PIBID e a importância dos conhecimentos construídos na prática e em todos os espaços de aprendizado e reflexão do futuro professor.

\subsection{Formação Inicial de Professores de Matemá- tica}

Em estudos a respeito da formação inicial do professor de Matemática, por exemplo, Cyrino (2008) destaca que a formação inicial da maioria dos professores está centrada na aplicação de teorias e técnicas científicas, onde na formação inicial, primeiro trabalhase com conteúdos científicos-culturais (conteúdos a ensinar) e depois com conhecimentos psicopedagógicos (como atuar na sala de aula).

Nesse sentido, os professores têm uma formação restrita a habilidades em currículos e programas específicos de área. Sendo assim são preparados, durante a graduação, para serem conhecedores da matemática e não para ensinarem matemática. De acordo com as Diretrizes Curriculares Gerais para a Formação de Professores da Educação Básica, em nível superior, curso de licenciatura, de graduação plena, Parecer CNE/CP 9/2001 e com as Diretrizes Curriculares Nacionais para a formação em cursos de licenciatura, Resolução RES $\mathrm{CNE} / \mathrm{CP} 2 / 2015$, tendo em vista as necessidades educacionais do país, a revisão da formação de professores para a educação básica é um desafio a ser enfrentado de imediato, de forma a assegurar a concretização do direito do aluno de aprender na escola.

Nesse sentido, o professor de Matemática deve ter, além do domínio amplo do conteúdo a ser ensinado, a habilidade de escolher e utilizar metodologias diferenciadas capazes de facilitar a aprendizagem matemática dos alunos. A respeito dos cursos de Licenciatura, Mizukami (2008) destaca que devem oferecer aos futuros professores uma consistente formação teórica e prática para que possibilite sustentação ao processo de aprendizagem e desenvolvimento profissional ao longo do seu percurso docente.

É função da formação inicial ajudar aos futuros professores a compreenderem esse processo e a conceberem a profissão não-reduzida ao domínio de conceitos de uma área específica, mas ampliando igualmente o desenvolvimento de habilidades, atitudes, comprometimento, investigação da própria atuação, disposição de trabalhar com os pares, avaliação de seus próprios desempenhos e procura constante de formas de melhoria de sua prática pedagógica em relação a populações especificas com as quais interage (MIZUKAMI, 2008, p. 216).

Dessa forma, na formação de professores é importante propor situações que levem à reflexão sobre a prática docente, visto que o professor é o principal agente responsável pela educação de seus alunos, e por isso deve estar muito bem preparado e em constante formação. De acordo com Curi (2011), um dos principais desafios a serem enfrentados, se quisermos proporcionar uma formação de qualidade aos futuros professores, especificamente aos de Matemática que ainda não estão em atuação, é inseri-los no contexto escolar, numa prática reflexiva - reflexão na ação e sobre a ação (SCHÖN, 2000).

Ou seja, na realização de tarefas profissionais, onde não se busque aplicar conhecimentos ou teorias aprendidas, mas aprender no, com e sobre o contexto das práticas, para melhorar a formação do professor pela relação teoria e prática, visando promover a iniciação á docência dos estudantes de licenciatura. Nessa perspectiva e com o objetivo de melhorar a formação do professor pela relação teoria e prática, visando promover a iniciação à docência aos estudantes de licenciatura das instituições de ensino superior, o Ministério da Educação (MEC) institui o Programa Institucional de Bolsa de Iniciação à Docência - PIBID.

\subsection{PIBID e Subprojeto Matemática do IFCE- Cam- pus de Canindé}

O Programa Institucional de Bolsa de Iniciação à Docência - PIBID é uma iniciativa da Coordenação de Aperfeiçoamento de Pessoal de Nível Superior - CAPES, que visa aperfeiçoar e valorizar a formação de professores para a educação básica, propondo a inserção de estudantes de licenciaturas no contexto das escolas públicas e objetivando fortalecer a sua formação acadêmica.

Por meio da Portaria Normativa Capes $\mathrm{n}^{\mathrm{o}} 122 \mathrm{de}$ 16/09/2009, foi instituído o Programa PIBID, que tem por finalidade fomentar a iniciação à docência, contribuindo para o aperfeiçoamento da formação de docentes em nível superior e para a melhoria da qualidade da educação básica (BRASIL, 2009).

O subprojeto "Re-construindo conhecimentos matemáticos”, do IFCE, Campus de Canindé, escolhido para a investigação, teve início em 2012, e conta hoje com a participação de 20 bolsistas ID Iniciação à Docência), 2 supervisores, 1 professor-formador voluntário e 1 coordenadora de área, e desenvolve ações formativas em duas escolas da rede pública estadual de ensino de Canindé-CE.

O projeto mencionado apresenta, como proposta, o aperfeiçoamento dos futuros professores de matemática a partir das práticas desenvolvidas nas escolas, e, consequentemente, contribuir com a aprendizagem matemática dos alunos dessas escolas. Para isso, o subprojeto consiste em oportunizar ações que favorecem práticas 
pedagógicas que proporcionam aos licenciandos uma postura reflexiva sobre o ensino e aprendizagem da matemática.

Na perspectiva de Ribeiro (2013), o PIBID é um programa que repercute de maneira positiva na formação docente de todos os envolvidos: formador, supervisor e futuro professor de matemática, visto que proporciona a este reflexão a respeito da prática pedagógica, inserindo os licenciandos ainda na condição de alunos, em uma real situação do ensino da matemática.

\subsection{Conhecimentos da Docência}

Neste tópico apontamos aspectos do modelo teórico que irá fundamentar as análises dos dados da pesquisa empírica. No que concerne ao conhecimento do professor esta pesquisa buscou apoio nos estudos de Shulman (1986, 2005), que anuncia os tipos de conhecimentos necessários para a docência.

Paiva (2008) aponta que os conhecimentos e competências adquiridos pelos alunos nos cursos de licenciaturas, na maioria das vezes, são insuficientes para exercer a docência. Nessa perspectiva a formação inicial do professor é, portanto, apenas uma etapa do processo necessário para a construção da sua identidade profissional.

Assim, para Cyrino (2008) é necessário buscar uma formação que permita aos futuros professores vivenciar e refletir a respeito da construção dos conhecimentos necessários a sua prática docente. "A Formação Inicial age como um alicerce na formação pedagógica do professor. É nesse período que o individuo irá construir a base de seu conhecimento pedagógico especializado para o início de sua profissionalização" (D’ÁGUA e ANDRADE, 2010, p. 54).

Em relação à construção do conhecimento matemático pelo licenciando, Paiva (2008) afirma que acontece como processo, estabelecendo relações entre conhecimentos anteriores e novos, atribuindo significados ou ampliando o que já se sabe, levando em conta os aspectos históricos e sociais que circundam esses conhecimentos.

Curi (2011), apoiada em Paiva (2008), salienta que os conhecimentos do professor para ensinar possuem um caráter evolutivo e contínuo, provenientes de várias fontes e construídos ao longo da vida. Destaca, ainda, que o professor deverá conhecer o conteúdo e as formas de produção do mesmo, "o professor deve ser aquele que faz, sabendo como e quando fazer" (CURI, 2011, p. 93). Nessa perspectiva, Mizukami (2008) destaca como são lentos os processos de aprendizagem da docência e do desenvolvimento profissional do professor, que vêm desde antes da formação na licenciatura e continuam por toda a vida em diversos espaços.

Conscientes disso, tomamos como referência, neste trabalho, as sete vertentes do conhecimento do professor para ensinar a disciplina, segundo Lee Shulman (2005). Essas vertentes são: Conhecimento do conteúdo; Conhecimento didático; Conhecimento do currículo; Conhecimento didático do conteúdo; Conhecimento dos estudantes e suas características; Conhecimento dos contextos educativos; Conhecimento dos objetivos.

Em Conhecimento do Conteúdo, Shulman (2005) refere-se aos conteúdos da disciplina que o professor leciona. O professor deve compreender a disciplina que vai lecionar e relacioná-la com outras áreas do conhecimento. No que se refere ao Conhecimento Didático, Shulman (2005) revela que são os princípios gerais e as estratégias de gestão e organização da sala de aula e da disciplina. É uma combinação entre o conhecimento da disciplina e o conhecimento do "modo de ensinar".

O Conhecimento Curricular, para Shulman (2005), diz respeito ao professor ter uma vasta compreensão dos programas curriculares e dos materiais didáticos disponíveis para ensinar sua disciplina. Conhecimento Didático do Conteúdo, segundo Shulman (2005), nasce na interseção entre a matéria a ser ensinada e a pedagogia. Está relacionado ao conhecimento de estratégias de ensino, onde o professor tem o intuito de tornar os conteúdos mais acessíveis para os seus alunos.

No que se refere ao Conhecimento dos Estudantes e suas Características, Shulman (2005) destaca como sendo o conhecimento de como os alunos aprendem no contexto onde estão inseridos e os conhecimentos prévios que os alunos trazem para as situações de aprendizagem. No que concerne ao Conhecimento dos Contextos Educativos, Shulman (2005), destaca que está relacionado ao ambiente e às características culturais das comunidades onde estão inseridos os estudantes e as instituições de ensino.

Conhecimento dos Objetivos, Metas e Valores Educacionais e seus Fundamentos Filosóficos e Históricos, Shulman (2005), releva que este conhecimento se relaciona à compreensão da escola na história a fim de elucidar metas, objetivos e valores que instrumentalizam a prática docente.

O estudo das sete vertentes do conhecimento apresentadas por Shulman (2005) nos fez pensar sobre que conhecimentos são construídos pelos licenciandos em Matemática do IFCE - Campus de Canindé mediante atuação no PIBID. 
CONHECIMENTOS DOCENTES DE LICENCIANDOS EM MATEMÁTICA NO ÂMBITO DA FORMAÇÃO E AÇÕES DESENVOLVIDAS NO PIBID DO IFCE CANINDÉ

\section{METODOLOGIA}

A abordagem metodológica da investigação ora apresentada foi a pesquisa qualitativa e o método um estudo de caso, baseado em Stake (1995 apud André, 2005), quando afirma ser este um estudo das características particulares mas também da complexidade de um caso específico e singular e que conduz ao entendimento das atividades desse caso dentro de circunstâncias importantes. E, ainda, em André (2005), que reconhece o estudo de caso educacional como o estudo profundo de um fenômeno da educação enfatizando sua singularidade e os princípios e métodos da etnografia. Não afirmamos ter usado estes últimos nesta pesquisa, mas houve uma aproximação, visto que todo o processo foi conduzido por pesquisadores também envolvidos com o fenômeno em estudo, sendo parte do grupo investigado.

De acordo com essas definições e características, investigamos o objeto desta pesquisa, que foram os conhecimentos docentes de alunos do curso de Licenciatura em Matemática do IFCE - Campus de Canindé, a partir de sua participação como bolsistas do PIBID.

Realizamos uma análise dos documentos do PIBID e do Relatório de Atividades e uma pesquisa de campo, onde utilizamos, como instrumento de coleta de dados, um questionário semiestruturado. Esse questionário foi construído com base na questão central e nos objetivos de pesquisa já elencados neste texto e nas categorias de análise discutidas no referencial teórico deste trabalho, mas deixando, conforme propõe Guerra (2006), também abertura para outras categorias ou subcategorias que surgissem no decorrer do processo de organização, leitura e análise dos dados.

Os sujeitos da pesquisa foram os 19 graduandos/bolsistas da licenciatura em matemática do IFCE/Canindé, participantes do subprojeto PIBID durante o período da pesquisa empírica - preparação e realização (junho a julho de 2015). O critério utilizado para a escolha dos sujeitos-pesquisados foi a obrigatoriedade de estarem atuando como bolsistas PIBID no Subprojeto "Reconstruindo conhecimentos matemáticos" do IFCE - Campus de Canindé.

Utilizamos, neste trabalho, as categorias de base do conhecimento docente de Shulman (2005), como categorias principais de análise para identificar conhecimentos de conteúdo, conhecimento didático, conhecimento didático do conteúdo e conhecimento dos estudantes e suas características, mobilizados pelos licenciandos em matemática do IFCE - Campus de Canindé no âmbito do PIBID.

Para iniciar a parte empírica da pesquisa fizemos contato pessoal com cada bolsista, que foi convidado a participar da pesquisa. Ao aceitar eles assinaram o Termo de Consentimento Livre Esclarecimento TCLE, de acordo com a Resolução 466, de 12 de Dezembro de 2012 , que versa sobre a pesquisa com seres humanos. Após esses procedimentos foram entregues os questionários para os bolsistas que consentiram em participar da pesquisa.

A aplicação do questionário ocorreu em duas fases, pela dificuldade de reunir os sujeitos pesquisados, pois estes estudam em turnos diferentes, sendo manhã e tarde. Dessa forma, enviamos e-mail para todos os graduandos/bolsistas do PIBID matemática, solicitando a sua participação na aplicação do questionário da pesquisa, ressaltando os dias e horários para aplicação.

O questionário foi composto por questões abertas e fechadas. As questões de 01 a 02 são do tipo fechadas e que abordam a identificação dos sujeitos pesquisados, tempo de ingresso no curso de licenciatura, tempo de docência e ano de ingresso no Programa PIBID. As questões de 03 a 06 são semiabertas e abordam a motivação para ingressar no PIBID, as atividades desenvolvidas no âmbito do PIBID, os aprendizados adquiridos a partir da experiência no PIBID, que poderiam ser incorporados na identidade docente e ainda os aprendizados construídos ou ressignificados por eles, quer sejam de matemática, para ensinar matemática ou sobre a educação escolar. Neste texto apresentamos e discutimos um recorte composto pela caracterização dos sujeitos (questões 1 e 2) e as quatro categorias de conhecimentos mencionadas (questões 5 e 6).

\section{DISCUSSÃO DOS RESULTADOS}

\subsection{Perfil dos sujeitos investigados sobre a expe- riência docente na área de ensino de matemá- tica}

Iniciamos a organização dos dados coletados por uma caracterização dos 19 sujeitos da pesquisa. Quanto ao gênero, 12 são do sexo feminino e 07 do sexo masculino. Suas idades variam entre 21 e 30 anos, numa média aproximada de 24 anos de idade. Em relação ao tempo de atuação no PIBID foi revelado que 09 são bolsistas há 3 anos, e 10 são bolsistas no período entre 1 e 2 anos. Eles estão em diferentes fases do curso de Licenciatura em Matemática, lócus dessa pesquisa. Do total de 19 bolsistas, 06 cursam o $5^{\circ}$ semestre, 01 cursa o $6^{\circ}$ e 12 cursam o $8^{\circ}$.

Todos os sujeitos que participaram do estudo tiveram suas identidades preservadas, conforme requer a ética na pesquisa. Dessa forma, nos referimos a eles utilizando a nomenclatura $\mathrm{Bi}$, com i variando de 1 a 19 , como por exemplo: $\mathrm{B} 1$ = Bolsista 1 e assim sucessivamente. 

DESENVOLVIDAS NO PIBID DO IFCE CANINDÉ

Quando questionamos sobre possuir experiência docente na aréa de ensino de matemática, 08 dos 19 sujeitos investigados relataram atuar ou terem atuado como professores da educação básica. O tempo de docência varia entre 3 meses e 2 anos e meio. A atuação de modo geral, foi como professores em escolas municipal e estadual da rede pública e escolas da rede privada de ensino.

Dessa forma, podemos verificar que 11 dos sujeitos investigados, ou mais de $50 \%$ desse universo obteve seu primeiro contato com a docência a partir da experiência no PIBID. A inserção desses bolsistas no seu futuro campo de atuação é um dos objetivos do PIBID, pois este busca proporcionar aos estudantes das licenciaturas o primeiro contato com a docência, a partir da aproximação com o ambiente escolar, logo no início do curso de licenciatura e assim auxiliar o professor iniciante no ingresso da profissão (BRASIL, 2010).

A partir da análise dos dados das questões subsequentes será possível termos esclarecimentos a respeito dos conhecimentos construídos e explorados pelos sujeitos investigados a partir das vivências no PIBID, o qual promoveu, para a maioria desses sujeitos, a primeira experiência no trabalho característico ao exercício profissional.

\subsection{Aprendizados construídos e/ou ressignifica- dos a partir da atuação no PIBID}

Nas duas últimas perguntas do questionário, buscávamos que os bolsistas respondessem sobre os aprendizados construídos e/ou ressignificados a partir da experiência no PIBID. Para já tentar que eles revelassem a maior parte possível de aspectos desses aprendizados, pedimos na questão 5 os aprendizados que poderiam ser ou foram incorporados na sua identidade docente (aspectos profissionais e/ou pessoais); e na questão 6 os aprendizados de matemática, para ensinar matemática e sobre a educação escolar de forma mais geral.

Ao ler e organizar esses dados, percebemos que havíamos tentado separar algo que para os bolsistas está muito imbricado, os aprendizados objetivos (de matemática, para ensinar etc.) e aqueles mais subjetivos, que influenciam ou influenciarão em suas escolhas e sua identidade docente.

$\mathrm{Na}$ análise desse material buscamos relação entre aprendizados descritos pelos sujeitos da pesquisa e as categorias de base do conhecimento preconizadas por Shulman (2005). A seguir apresentamos uma compilação das respostas dadas às duas questões, que foram organizadas, segundo a reunião de significados semelhantes, na mesma categoria, e, ainda, em alguns casos em mais de uma categoria, como o próprio Shulman afirma, já que esses conhecimentos se interpenetram. São tecidas também reflexões decorrentes dos conhecimentos que emergiram a partir das falas dos sujeitos investigados. Passaremos agora a analisar quatro (4) dos conhecimentos citados na fundamentação teórica deste texto, que emergiram a partir das falas dos sujeitos da pesquisa.

Em relação ao Conhecimento do Conteúdo a maioria dos sujeitos relatou a necessidade de estudar conteúdos que não tinham aprendido na Educação Básica ou até mesmo não tinham visto, pois foi inteiramente necessário para o desenvolvimento das atividades do projeto, como enfatiza $\mathrm{B} 4$ :

\footnotetext{
Vários conteúdos do ensino médio que não havia visto ou até mesmo que não havia aprendido que foi necessário (re) ver para que desempenhasse a contento as atividades propostas. (B4)
}

O relato acima indica que o aluno percebe e questiona as lacunas, em seus conhecimentos matemáticos, trazidas da Educação Básica. Percebemos, por meio das falas dos sujeitos, que a oportunidade de inserção no campo profissional está contribuindo para que tais lacunas sejam preenchidas, à medida que estes tiveram que voltar a estudar os conteúdos da Eduaçação Básica para desenvolver as atividades do PIBID.

De acordo com Shulman (1986, 2005), o conhecimento de conteúdo é o conhecimento chave que forma a base de conhecimento do professor, pois os professores devem possuir as habilidades e competências necessárias para melhor se apropriarem daquilo que é inerente a sua formação onde não é possível ensinar aquilo que não se sabe.

Dentro deste contexto, a fala de (B5), nos chamou bastante atenção:

Muitos conhecimentos foram construidos e ressignificados, entre eles, relacionados à análise combinatória, funções, proporcionalidade, geometria plana e espacial e aritmética básica.

Diferente dos outros sujeitos que relataram de modo geral a construção e exploração de conteúdos matemáticos, B5 descreveu os conteúdos de matemática os quais foram ressignificados ou até mesmo aprendidos por ele pela primeira vez. Por meio da análise, identificamos, nessa fala, a necessidade dos bolsistas conhecerem os conteúdos específicos de sua disciplina, o que vai ao encontro das ideias de Shulman (2005), uma vez que o professor necessita desse conhecimento para julgar o que é mais adequado para a sua prática pedagógica. Ainda, de acordo com Curi (2011), o professor tem a responsabilidade de conhecer o conteúdo específico de sua área e como o mesmo se produz, dominando com segurança esses conteúdos e as condições de ensino. 


\section{CONHECIMENTOS DOCENTES DE LICENCIANDOS EM MATEMÁTICA NO ÂMBITO DA FORMAÇÃO E AÇÕES}

DESENVOLVIDAS NO PIBID DO IFCE CANINDÉ

Mesmo porque, o conhecimento do conteúdo matemático está interligado, ou seja, não se pode dominar um determinado conhecimento específico sem antes ter dominado um conteúdo anterior, haja vista esse conhecimento anterior ser pré-requisito. Por isso, também, muitos alunos do ensino fundamental e médio têm inúmeras defasagens quando chegam, por exemplo, no Ensino Superior.

Para os sujeitos investigados não está sendo exceção, pois essa experiência no PIBID serviu para que todos pudessem ter uma compreensão acerca dessa realidade e, sobretudo, uma criticidade quanto a suas formações na escola básica, munindo-os da responsabilidade de sempre rever cada conteúdo anteriormente visto e assim sempre se atualizar, ressignificando conhecimentos e recriando-os.

Em tese, os sujeitos da pesquisa irão atuar na educação básica, agora na condição de professores, podendo então procurar contribuir com a melhoria da qualidade dessa educação, mediante a aplicação em sala de aula dos conhecimentos do conteúdo de sua área através de práticas pedagógicas diferenciadas.

No que diz respeito ao Conhecimento Didático, os sujeitos relataram que por meio do PIBID puderam: aprender a planejar as aulas, a trabalhar diretamente com os alunos, a usar materiais didáticos diversificados para uma aprendizagem mais efetiva por parte dos seus alunos e formas diferentes de avaliar os alunos.

Segue-se uma fala que ilustra os aprendizados que mencionamos:

Como realizar projetos; Como planejar uma aula e controlar o tempo de duração de uma aula; Como trabalhar diretamente com os alunos, levando em consideração o tratamento, respeito e como controlá-los em situações de indisciplina. (claro que não aprende completamente, mas já tenho uma noção); Aprendi muitas coisas com o PIBID, basicamente tudo que sei hoje a respeito de prática em sala de aula. (B3)

Corroborando com o nosso estudo, podemos mencionar autores como Libâneo (1994), Pimenta e Lima (2011), que destacam a importância da articulação entre a teoria e prática e o quanto são indispensáveis as vivências práticas para a formação dos profissionais da educação. No relato apresentado acima, percebemos que através da atuação no PIBID foi possível fazer o elo entre a teoria estudada nas disciplinas pedagógicas do curso e as práticas desenvolvidas nas escolas, de modo a realizar uma reflexão dessas práticas.

Destacamos outra fala que ressalta a variação metodológica no ensino:

Aprendi novas formas de repassar cada conteúdo, desenvolvi o prazer em ensinar." (B16)
Podemos verificar, através dessa fala, que a partir do momento em que o sujeito da pesquisa nos diz que aprendeu "novas formas de repassar cada conteúdo", isso diz respeito às diferentes estratégias utilizadas para o ensino do mesmo. Chamamos a atenção, no entanto, para a palavra "repassar", pois há discussões da didática e da psicologia da aprendizagem que não consideram a aula ou o ensino um mero repasse, mas uma ação conjunta em que professor e alunos aprendem e ensinam mutuamente. Libâneo (1994), por exemplo, salienta que o professor deve garantir a unidade didática entre ensino e aprendizagem, por intermédio do processo de ensino.

Sobre o processo de ensino, e mais especificamente o desenvolvimento de diferentes métodos de dar aula, o uso diversificado de recursos e a elaboração de planos de aulas e planos de cursos, os sujeitos pesquisados relataram vários aprendizados a partir das ações no PIBID.

Podemos evidenciar a construção desses conhecimentos na seguinte fala:

Melhorei minha metodologia em sala de aula [...] Aprendi a incorporar o uso de materias manipulaveis, e novas tecnologias, tornando minha aula mais dinâmica. (B8)

Como podemos analisar, os sujeitos destacam conhecimentos das diferentes metodologias que podem ser trabalhadas em sala de aula a fim de facilitar o ensino-aprendizagem dos alunos.

Conforme Hilgeman et al (2013), o processo de construção e utilização de material didático, tornase uma atividade que proporciona aos licenciandos assumir-se autor de suas aprendizagens e dos recursos que oferecerão aos alunos, com um olhar crítico para o modo de trabalhar com as diferentes metodologias, de modo a construir novos conhecimentos.

Ainda sobre a fala de B16: "Aprendi novas formas de repassar cada conteúdo, desenvolvi o prazer em ensinar." Ressaltamos que o sujeito admite a contribuição da participação no PIBID para o desenvolvimento "do prazer em ensinar", ou seja, para a identificação com a docência como exercício profissional, tendo em vista que este nem sempre corresponde à formação inicial do licenciando. Dessa forma, a partir do relato de (B16), é possível evidenciar que, por meio da sua participação no PIBID, o interesse pela área de ensino, por se tornar professor, começa a ser despertado. Resultados como esse coadunam com as pesquisas de Capistrano, Macêdo e Macêdo (2012).

Já acerca do Conhecimento Didático do Conteúdo, de modo geral os sujeitos da pesquisa relataram 
CONHECIMENTOS DOCENTES DE LICENCIANDOS EM MATEMÁTICA NO ÂMBITO DA FORMAÇÃO E AÇÕES DESENVOLVIDAS NO PIBID DO IFCE CANINDÉ

a aprendizagem das diferentes metodologias que facilitam o ensino e aprendizagem de matemática.

Entre as falas destacamos o relato do sujeito B2, onde este nos diz que:

A partir do Pibid adquiri experiências em relação a ensinar conteúdos de matemática, e as diferentes metodologias. Usando recursos que ajudam a ensinar matemática, como: jogos, tecnologias e etc. (B2)

Como podemos verificar a partir da fala do sujeito, este não só teve no PIBID uma oportunidade de adquirir experiências, no que diz respeito ao ensino dos conteúdos de matemática, como também de utilizar diferentes tendências metodológicas da Educação Matemática de modo a facilitar o ensino e ainda favorecer, para os alunos das escolas parceiras ao projeto, uma aprendizagem a partir de outras estratégias e recursos.

De acordo com os estudos de Mendes (2008), é de suma eficácia o ensino de matemática lançar mão de diferentes tendências metodológicas, de acordo com cada conteúdo e fase de desenvolvimento e aprendizagem do aluno.

Nos detemos agora na fala de B5, onde enfoca o PIBID como espaço para relacionar a teoria com a prática de sala de aula:

Tudo que hoje considero saber sobre o ensino da Matemática é fruto de minhas práticas no PIBID. Este programa se constituiu como o espaço ideal para relacionar as teorias estudadas com a realidade. (B5)

A fala do sujeito B5 é muito forte, quando este nos diz que "tudo que hoje considero saber sobre o ensino da Matemática é fruto de minhas práticas no PIBID”. Essa passagem deixa clara a contribuição do programa para a construção do conhecimento didático do conteúdo pelo sujeito pesquisado, pois este teve no PIBID a oportunidade de trabalhar com diferentes metodologias para o ensino da matemática, tendo através do PIBID o seu primeiro contato com a docência.

Corroborando com os estudos de Shulman (1986), o professor não deve dominar somente os conteúdos de sua disciplina, estes são necessários, mas não são suficientes. Saber um assunto para ensiná-lo requer mais do que saber seus fatos e conceitos.

Ainda segundo o autor, o professor deve também compreender os princípios e estruturas da matéria de ensino, pois este deve não somente compreender que algo é assim; deve compreender mais profundamente porque é assim.

Corroborando com os estudos de Schön (2000) a respeito da prática reflexiva, vemos que à medida que o PIBID aproxima esses licenciandos do seu futuro campo de atuação, os estudantes aprendem fazendo e refletindo sobre esse fazer, onde estes assumem o ofício da profissão, aperfeiçoando-se.

Pertinente ao Conhecimento dos Estudantes e suas Características, os sujeitos relataram que aprenderam a lidar e trabalhar com os diferentes tipos de alunos. Como podemos observar na fala que se segue:

Aprendi a lidar com os alunos, suas expectativas, frustrações, manejo da sala de aula, etc. Cito que foi essa aprendizagem aquela que acho a mais importante dentre todas que aprendi, haja vista ser o aluno como um todo o foco do trabalho pedagógico de todo e qualquer professor. (B12)

Em seu relato B12 ressaltou o conhecimento sobre os alunos, avaliando esta aprendizagem como a mais importante adquirida por meio da atuação no PIBID. Ao citar que aprendeu a "lidar com os alunos, suas expectativas, frustrações, manejo da sala de aula", o sujeito incorpora a real finalidade do fazer docente: a reunião de competências técnicas, morais e intelectuais como meios para se aproximar da cognição, mas também da subjetividade dos alunos, haja vista o trabalho pedagógico fundamentar-se também na psicologia educacional, pelo conhecimento sobre as fases de desenvolvimento e aprendizagem dos alunos.

Em torno disso, Libâneo (1994) enfoca a interação professor-aluno como um aspecto primordial do trabalho pedagógico do professor, sempre visando alcançar os objetivos do processo de ensino, quais sejam: transmissão e assimilação dos conhecimentos, hábitos e habilidades. Por isso, trazer a figura do aluno para o centro da discussão do processo de ensino é fundamental para o professor que busca sucesso em sua práxis pedagógica. Outra fala que merece destaque dentro desta categoria diz respeito a $\mathrm{B} 19$, ao dizer:

É importante, quando o professor se depara com um aluno com dificuldades de aprendizagem e aos poucos este aluno vai superando suas complexidades, a sensação de que você está interferindo positivamente na educação do aluno é muito gratificante. (B19)

A fala de B19 ressalta a importância do professor, ao se deparar com alunos com dificuldades de aprendizagem, interferir nessas dificuldades, ajudando-os a superá-las, e como isso transmite a esse docente uma sensação de dever cumprido. Essas dificuldades, espeficificamente na disciplina de Matemática dizem respeito a diversos os problemas enfrentados pelos discentes quando do ensino e aprendizagem da mesma.

Ressaltamos, aqui, apenas os seguintes: falta de conhecimento e habilidades com a linguagem matemática e seus símbolos, falta de domínio das operações mentais básicas, como classificar, ordenar, separar, seriar, falta de compreensão das definições matemáticas, falta 
da prática de resolução de exercícios e problemas, impossibilitando, assim, a asimilação do conteúdo, falta de compreensão e habilidades de leitura e escrita, o que acarreta incompreesão dos problemas matemáticos que se apresentam, dentre outros. O subprojeto PIBID em discussão tem buscado proporcionar aos bolsistas uma percepção desses dilemas, para trabalhá-los em sintonia com os conhecimentos teóricos adquiridos na graduação, visando amenizá-los na realidade dos alunos das escolas parceiras.

\section{CONSIDERAÇÕES FINAIS}

Percebemos, no decorrer da realização deste trabalho, que a formação inicial dos professores contém desafios históricos, como a existência de currículos normativos dos cursos de licenciaturas, que apresentam primeiro os conteúdos teóricos e depois os conhecimentos necessários a atuar em sala de aula, enfatizando mais aqueles que estes. A persistência desse modelo formativo contradiz as recomendações legais atuais, incluindo os programas de formação inicial ou continuada de professores, que buscam incorporar as situações pedagógicas numa ligação entre a teoria e a prática, visando também atitudes reflexivas dos profissionais, investigação e análise do ambiente escolar.

Dentro desse contexto, o Programa Institucional de Bolsa de Iniciação à Docência - PIBID, como uma concretização da politica nacional de educação e mais especificamente de formação, busca, dentre outras coisas, promover a integração entre Educação Superior e Educação Básica, visando ao fortalecimento da formação inicial para a docência, solidificando e qualificando a formação, objetivando melhorar a qualidade da Educação Básica, inserção dos licenciandos em escolas públicas desde o ínicio da sua formação acadêmica, além de procurar desenvolver nos licenciandos aprendizados didático-pedagógicas como apoio na opção pela carreira docente.

A partir do que pudemos depreender da presente pesquisa, o PIBID promoveu, para a maioria desses sujeitos, a primeira experiência do trabalho característico ao exercício profissional, trazendo a possibilidade de construção de conhecimentos diversificados. Esse programa mostra-se, portanto, muito relevante para a formação do licenciando, aqui especificamente em matemática, haja vista a possibilidade de construção de conhecimentos relevantes à atuação docente, que deve acontecer durante a graduação, para munir o futuro professor de habilidades, repertório teórico-prático e experiências para enfrentar os desafios que a realidade escolar trará quando este licenciando estiver atuando, pois vai estar melhor preparado para compreeder esses dile- mas do que um aluno que não teve essa experiência.

Em relação às quatro categorias de conhecimento de base preconizadas por Shulman (2005), encontramos diversos indicadores destes nas respostas dos bolsistas. Sobre o Conhecimento do Conteúdo percebemos que os licenciandos parecem ter percebido a necessidade desse conhecimento e diante disso passaram a ter a prática de estudar conteúdos que não tinham aprendido na Educação Básica ou mesmo não tinham visto, mas estudálos na intenção de ensino. Ao rever esses conteúdos os mesmos procuravam suprir as lacunas existentes em sua formação básica, procurando melhorar acerca dessa realidade, ressignificando e recriando seus conhecimentos de Matemática.

Acerca do Conhecimento Didático, os licenciandos investigados aprenderam a planejar aulas, usar materiais didáticos diversificados e ainda diferentes metodologias e principalmente quando as utilizar. O Conhecimento Didático do Conteúdo destaca-se nos sujeitos investigados como o principal conhecimento adquirido pelos bolsistas, pois relaciona o conhecimento teórico que os mesmos obtiveram nas disciplinas da graduação com o conhecimento da prática de sala de aula desenvolvidos no decorrer do subprojeto, com o uso de diferentes metodologias/tendências da Educação Matemática.

Por sua vez, o Conhecimento dos Estudantes e suas Características oportunizaram aos bolsistas pesquisados se apropriarem de práticas necessárias no sentido de saber lidar com os diferentes tipos de alunos e situações, ou seja, conhecimentos que só poderiam ser adquiridos na prática de sala de aula.

A partir da presente pesquisa e dos sujeitos investigados, podemos afirmar que determinados conhecimentos têm sido adquiridos, construídos e ressignificados a partir de uma participação efetiva no Programa de Formação Inicial de professores PIBID, o que, além de outros fatores, o torna de extrema relevância na formação docente inicial atual.

Diante disso, as questões abordadas nesta pesquisa apresentam alguns aspectos importantes da formação e do trabalho docente. Procuramos contribuir para o aprofundamento das discussões de alguns aspectos que constituem a formação inicial do professor de matemática, e ainda, a contribuição de políticas públicas voltadas para a formação de professores, como o PIBID. Essas questões abrem a possibilidade para futuros apronfundamentos e novas pesquisas.

\section{REFERÊNCIAS}

ANDRÉ, M. E. D. A. Estudo de caso em pesquisa e avaliação educacional. Brasília: Líber Livro Editora, 
CONHECIMENTOS DOCENTES DE LICENCIANDOS EM MATEMÁTICA NO ÂMBITO DA FORMAÇÃO E AÇÕES DESENVOLVIDAS NO PIBID DO IFCE CANINDÉ

2005.

BRASIL. Portal do Programa Institucional de Bolsa de Iniciação à Docência - PIBID. Brasília: CAPES, 2008. Disponível em: <http: //www.capes.gov.br/educacao-basica/capespibid> Acesso em: 15 jan. 2015.

Portaria normativa $n .122$, de 16 de setembro de 2009. Dispõe sobre o PIBID Programa Institucional de Bolsa de Iniciação à Docência. Brasília: CAPES, 2009. Disponível em: <http://www.capes.gov.br/images/stories/download/ bolsas/PortariaNormativa122_PIBID.pdf> Acesso em: 15 jan. 2015.

Portaria Normativa n. 260, de 30 de dezembro de 2010. Normas gerais do Programa Institucional de Bolsa de Iniciação à Docência - PIBID. Brasília: CAPES, 2010. Disponível em: <http://www.capes.gov. br/images/stories/download/legislacao/Portaria260_ Pibid_301210_NomasGerais.pdf> Acesso em: 15 jan. 2015.

Parecer CNE/CP 9/2001, de 08 de maio de 2001. Diretrizes Curriculares Nacionais para a Formação de Professores da Educação Básica, em nível superior, curso de licenciatura, de graduação plena. Brasília: CNE, 2011.

Resolução n. 466, de 12 de dezembro de 2012. Diretrizes e normas regulamentadoras de pesquisas envolvendo seres humanos. Brasília: Ministério da Saúde, 2012. Disponível em: <http://bvsms.saude.gov.br/bvs/saudelegis/cns/2013/ res0466_12_12_2012.html>. Acesso em: 20 set. 2015.

. Resolução CNE/CP 2/2015, de 01 de julho de 2015. Define as Diretrizes Curriculares Nacionais para a formação inicial em nível superior (cursos de licenciatura, cursos de formação pedagógica para graduados e cursos de segunda licenciatura) e para a formação continuada. Brasília: CNE, 2015.

CAPISTRANO, K. da S.; MACÊDO, L. N. de; MACÊDO, A. A. M. Importância do projeto pibid na formação docente inicial: estudo de caso com bolsistas do pibid/química/ifce quixadá. In: Anais do VII CONNEPI. Palmas: [s.n.], 2012. Disponível em: <http://propi.ifto.edu.br/ocs/index.php/connepi/vii/ paper/view/2525/2294> Acesso em: 20 set. 2015.

CURI, E. A formação inicial para ensinar matemática: algumas reflexões, desafios e perspectivas. Rematec, Natal, v. 6, n. 9, p. 75 - 94, jul. 2011.
CURI, E.; PIRES, C. M. C. Pesquisas sobre a formação do professor que ensina matemática por grupos de pesquisa de instituições paulistanas. educaçãomatemática pesquisa. São Paulo, v. 10, n. 1, p. $151-189,2008$.

CYRINO, M. C. de C. T. Preparação e emancipação profissional do professor de matemática. In: NACARATO, A. M.; PAIVA, M. A. V. (Ed.). A formação do professor que ensina Matemática: perspectivas e pesquisa. 1. ed. Belo Horizonte: Autêntica, 2008.

D’ÁGUA, S. V. N.; ANDRADE, M. M. Formação e trabalho docente demandas e desafios. In: OLIVEIRA, C.; MARIM, V. (Ed.). Educação Matemática Contextos e Práticas Docentes. Campinas: Alínea, 2010. p. $50-57$.

GUERRA, I. C. Pesquisa qualitativa e análise de conteúdo: sentidos e forma de uso. São Paulo: Princípia, 2006.

HILGEMANN, C. M.; HAUSCHILD, C. A.; SCHMITT, F. E.; BERSCH, M. E.; FALEIRO, S. R.; GONZATTI, S. E. M. Vivências no pibid: contribuições à formação docente. In: HAUSCHILD, C. A.; HERBER, J.; KONRATH, A. R. (Ed.). Pibid/univates: articulando saberes e práticas entre universidade e escola. 1. ed. Porto Alegre: Evangraf, 2013. p. $31-40$.

LIBÂNEO, J. C. Didática. São Paulo: Cortez, 1994.

MENDES, I. A. Tendências metodológicas no ensino de matemática. Belém: EdUFPA, 2008. Disponível em: <http://www.ufpa.br/par/files/Modulos/vol41.pdf> Acesso em: 15 set. 2015.

MIZUKAMI, M. das G. N. Aprendizagem da docência: conhecimento específico, contextos e práticas pedagógicas. In: NACARATO, A. M.; PAIVA, M. A. V. (Ed.). A formação do professor que ensina Matemática: perspectivas e pesquisa. 1. ed. Belo Horizonte: Autêntica, 2008.

PAIVA, M. A. V. O professor de matemática e sua formação: busca da identidade profissional. In: NACARATO, A. M.; PAIVA, M. A. V. (Ed.). A formação do professor que ensina Matemática: perspectivas e pesquisa. 1. ed. Belo Horizonte: Autêntica, 2008.

PIMENTA, S. G. Professor reflexivo: construindo uma crítica. In: PIMENTA, S. G.; GHEDIN, E. (Ed.). 
Professor reflexivo no Brasil: gênese e crítica de um conceito. 7. ed. São Paulo: Cortez, 2012.

PIMENTA, S. G.; LIMA, M. S. L. Estágio e docência. 6. ed. São Paulo: Cortez, 2011. Revisão técnica José Cerchi Fusari. Coleção docência em formação. Série saberes pedagógicos.

RIBEIRO, S. S. Percepções de licenciandos sobre as contribuições do PIBID - Matemática. Dissertação (Mestrado Profissional em Educação) - Universidade Federal de Lavras, Lavras, 2013. 212 p.

SACRISTÁN, J. G. Consciência e acção sobre a prática como libertação profissional dos professores. In: NóVOA, A. (Ed.). Profissão Professor. Porto, Portugal: Porto editora, 1999.

SCHÖN, D. A. Educando o profissional reflexivo: um novo design para o ensino e a aprendizagem. Porto Alegre: Artes Médicas Sul, 2000. Tradução Roberto Cataldo Costa.

SHULMAN, L. S. Those who understand: knowledge growth in teaching. Educational Research, v. 15 , n. 2 , p. $4-14,1986$. Disponível em: $<$ http://www.fisica.uniud.it/URDF/masterDidSciUD/ materiali/pdf/Shulman_1986.pdf> Acesso em: 20 jan. 2015.

Profesorado. Revista de currículum y formación del profesorado, v. 9, n. 2, p. $4-14$, 2005. Disponível em: <http://www.ugr.es/ recfpro/rev92ART1.pdf> Acesso em: 26 jan. 2015. 